\title{
Adipocytes containing adipokines causes $\beta$-cell regeneration in previously streptozotocin induced hyperglycemic rats model
}

\begin{abstract}
Introduction:The aim of this study was to evaluate the effect protein containing adiponectin from the adipocytes on the regeneration of pancreatic $\beta$-cells in rates previously treated with (STZ). Therefore, adipocytes from different sources were extracted for protein (adipokines) and the effect was evaluated on pancreatic $\beta$-cell regeneration.

Methods: The protein extracts from trimmed off abdominal adipose tissues of meat sources, namely chicken, beef and lamb, were used in the present study. The fats were removed, and protein were isolated, and hydrolysate were prepared and injected to rats. The rats were induced hyperglycemia with streptozotocin (STZ) were divided into normal rats (Group-A), insulin treated rats (Group-B), protein containing beef adiponectin (PCBA) (Group-C), protein containing lamb adiponectin (PCLA) (Group-D), protein containing chicken adiponectin (PCCA) (Group-E) and no treatment hyperglycemic rats (Group-F). The rats were injected $30 \mathrm{mg}$ of the aforementioned proteins and pancreatic morphology was assessed two weeks post-treatment.
\end{abstract}

Results: The pancreas of the Group-A showed normal islets of Langerhans with abundant beta cells. In the no treatment rats (Group-F), islets were lower in cellular density compared to the control and treatment groups. The pancreas of Group-C, D and E rats showed islets and acinar cells that were comparable to the control. The pancreas of insulin-treated Group-B was similar in architecture to the control group.

Conclusions: The present study indicates that protein extracts containing adipokines from Adipocytes Containing Adiponectin Causes $\beta$-cell Regeneration in Rats

Keywords: protein extract, adipocytes, adiponectin, adipokines, $\beta$-cell, regeneration, rats
Volume 10 Issue 2 - 2020

\author{
Nuraniza Azahari, Nor Azwani Mohd-Shukri, \\ Muhammad Muzaffar Ali Khan Khattak \\ Department of Nutrition Sciences, International Islamic \\ University, Malaysia
}

Correspondence: Muhammad Muzuffar Ali Khan Khatak, Department of Nutrition Sciences, Kulliyyah of Allied Health Sciences, International Islamic University, Jalan Istana, Bandar InderaMahkota 25200 Kuantan, Pahang Darul Makmur, Malaysia, Tel +609-57I 5304, Fax +609-6776, Email muzaffar@iium.edu.my

Received: March 06, 2020 | Published: April 29, 2020
Abbreviations: PCBA, protein containing beef adiponectin;PCLA, protein containing lamb adiponectin; PCCA, protein containing chicken adiponectin

\section{Introduction}

\section{Adipocytes}

Adipocytes secretes various types of proteins that are considered physiologically/pathologically important. The pancreatic beta cell is an essential endocrine which mainly function to produce, store and secrete insulin to the body. This cell could be more precisely defined as a type of cell that is finely tuned to efficiently regulate blood glucose levels while maintaining the ability to adapt a wide range of stimulus and physiological changes. ${ }^{1}$

\section{Adipocytes as source of adipokines}

Adipose tissue is one of the largest fat depot in the body which secretes adipokines. The total amount of secreted adipokines from whole adipose tissue might affect the whole body. ${ }^{2}$ Many studies on direct pharmacological administration of adiponectin have been shown to reduce lipid and insulin concentrations as well as increase insulin receptor expression in obese diabetic mice. ${ }^{3}$ Another study has reported that activation of $\beta$-cells after treatment with globular adiponectin induces endothelial cell activation by stimulation of the sphingosine kinase signalling pathway.
Thus, the present study was designed to evaluate the efficacy of protein extracts from these wasted adipose tissues in meat of beef, lamb and chicken as cheaper sources that could provide baseline results for future studies with a hope for future therapeutic/prevention strategies for obesity, insulin resistance and metabolic diseases.

\section{Methods}

The adipocytes from these sources were chosen for this study because chicken, beef and lamb were easily found and normally preferred for daily consumption by the Malaysian people and elsewhere in the world.

Sample preparation for protein extraction:The abdominal adipose tissues from beef, lamb and chicken were removed then minced into 5-10 mg slices with surgical blade. Followed by rinsing with ice-cold phosphate-buffered saline (PBS) solution. As a preliminary study, small pieces of the minced chicken, beef and lamb adipose tissues were freeze dried for 24 hours in order to remove excess water content.

Delipidation of tissue lysate:The chicken, beef and lamb adipose tissues then underwent the process of elimination of lipid (delipidation process). Delipidation of the tissue lysates were performed by chloroform/methanol extractions, with some modifications ${ }^{5,6}$ Homogenization of tissue samples were performed in a ceramic mortar in $500 \mathrm{ml}$ of isolation medium $(50 \mathrm{mM}$ Tris, $150 \mathrm{mM} \mathrm{NaCl}, 0.2 \mathrm{mM}$ EDTA, and protease inhibitors) and $1875 \mathrm{ml}$ 
of a chloroform/methanol (1:2) mixture. Homogenized tissues were then transferred to a glass tubes and mixed sporadically while kept on ice for 10-15 minutes. The homogenate was diluted with $625 \mathrm{ml}$ of chloroform and $625 \mathrm{ml}$ of water to change the water/chloroform/ methanol ratio from $0.8: 1: 2-1.8: 2: 2$ in the final organic solution. Lipid (lower) phase was collected by centrifugation at $1000 \mathrm{xg}$ for 5 minutes at $4^{\circ} \mathrm{C}$. Aqueous (upper) phase and protein disk between two phases were used separately for the protein analysis. ${ }^{6}$

Protein precipitation:Proteins were precipitated from the aqueous phase by using a $10 \%$ TCA protocol. This was used to precipitate proteins and get rid of from the contaminants such as salt, nucleic acid or lipids. Proteins were precipitated by the addition of 3 volumes of $10 \%$ trichloro acetic acid (TCA) in acetone at $-20^{\circ} \mathrm{C}$ overnight. This was followed by centrifugation at $7500 \mathrm{x}$ g for 30 minutes at $4^{\circ} \mathrm{C}$ in the following day. The supernatant was discarded, and the pellet was washed twice with $1 \mathrm{ml}$ of ice-cold acetone. All the acetone was then completely removed ${ }^{7}$. The pellet was dried either at room temperature or under a fume hood for 1-2 hours to ensure complete removal of the water and solvents. The pellet was then stored at $-20^{\circ} \mathrm{C}$ for subsequent use.

\section{Preparation of buffer and streptozotocin}

Sodium citrate buffer preparation:To prepare the buffer, $0.4 \mathrm{~g}$ of sodium citrate was dissolved in $50 \mathrm{ml}$ of distilled water followed by $0.625 \mathrm{~g}$ of citric acid and stirred well. Then, $0.55 \mathrm{~g}$ of sodium chloride $(\mathrm{NaCl})$ was dissolved in $50 \mathrm{ml}$ of distilled water. Lastly, 0.5 $\mathrm{ml}$ of $\mathrm{NaCl}$ solution was pipetted into a sodium citrate buffer and the solution was stirred well. Buffer was made fresh for every group of injections. Appropriate amount of buffer was placed in sterile conical tubes.

Streptozotocin (STZ) preparation:The STZ to be injected was prepared in a dark room to protect from light. Appropriate amount of $70 \mathrm{mg} / \mathrm{kg} \mathrm{BW} \mathrm{STZ}$ was weighed and then diluted in the sodiumcitrate buffer, before being placed into a sterile Falcon tube. This solution was then covered with aluminium foil (light sensitive). The STZ/buffer was mixed to be ready for swift injection as the drug degrade within 15-20 minutes in solution.

Animal preparation and induction of hyperglycaemia: All animal experiments were carried out in compliance with the Institutional Animal Care and Use Committee (IACUC). The protocol was approved by the committee of Institutional Animal Care \& Use Committee (IACUC), Kuantan Campus, International Islamic University Malaysia (IIUM) with IACUC Approval:IIUM / IACUC Approval / 2016 / (9) (55) which is guided by the principles set out by the Malaysian Code of Practice for the Care and Use of Animals for Scientific Purposes. The experiments were carried out on 36 thirty males Sprague Dawley rats with the weight range of 180-250 $\mathrm{g}$ with an age range of 8-12 weeks-old from aA Sapphire Enterprise (Seri Kembangan, Selangor, Malaysia). Male rats were chosen for this experiment because they have been reported to be more prone to STZ-induced cytotoxicity than female. Upon arrival, rats were weighed and randomly housed in the cages, put in a secured animal room in a controlled environment at $24^{\circ} \mathrm{C}$ and was exposed to 12 -hour with controlled light and dark cycles. Rats were fed with standard normal pellet diet (NPD), which comprised of a chow diet (Cargill Feed SDN BHD) that meets the nutrient requirements of rats. After acclimatization for 1 week, the animals were assigned into six groups (six rats/group), where six6 rats per group were placed according to their body weight. Access to chow diet and water was unrestricted for all groups. Chow diet was given in the form of pellet. Hyperglycaemia was induced by single intraperitoneal injections at a dose of $70 \mathrm{mg} / \mathrm{kg}$ of body weight which was freshly prepared by diluting Streptozotocin (STZ; Sigma-Aldrich Corporation, USA) in ice-cold $0.5 \mathrm{~mol} / \mathrm{L}$ citrate buffer ( $\mathrm{pH} 4.5$ ). Rats were fasted 4 hours prior to STZ injection. An appropriate amount of STZ solution was injected until the final dosage of $70 \mathrm{mg} / \mathrm{kg}$ body weight was achieved. Next, the rats could regain consciousness and were placed in their respective cages. The same experimental procedure was repeated for each animal.

Diabetic status:Blood glucose level was measured from the tail vein using a glucometer (ACCU-CHECK Active) at day 2, 5, 7 and day 10 after induction for possible hyperglycaemia. Rats with blood glucose level above $11.0 \mathrm{mmol} / \mathrm{L}$ were considered to have hyperglycaemia and were used for further study by initiating the treatment. The animals were then divided again into 6 groups, each according to blood glucose levels (Table 1). The doses of protein $(30 \mathrm{mgs} / \mathrm{kg}$ body Weight) containing adiponectin were selected based on an acute study reported that on previous studies carried out on rodents..$^{8-10}$ The protein extracts were administered into the peritoneal cavity by intraperitoneal injection with a single dose for 14 days. Intraperitoneal administration method was used in this study because of this could produce highest bioavailability of extracts due to its avoid the first-pass effect of hepatic metabolism which occur commonly with oral gavage. This method also avoids some of the unpredictability associated with oral absorptive process.

Histological analysis of pancreas:The pancreas was harvested from the sacrificed rats after dissection, weighed and then washed with Phosphate Buffered Saline (PBS). The samples of pancreas were grossed and fixed into a cassette. The cassette was then placed and processed in a paraffin tissue processing machine. The process started with tissue fixing in $10 \%$ buffered formalin for two hours.

Tissue processing:The fixed pancreas was placed in a cassette prior to tissue processing for 28 hours using Leica Tissue Processor. The tissues were dehydrated in an ascending grade of isopropyl alcohol, whereby the pancreas was first immersed in $80 \%$ isopropanol overnight, followed by immersion in $100 \%$ isopropyl alcohol for 1 hour. Next, the dehydrated tissues were placed into paraffin wax at 65 ${ }^{\circ} \mathrm{C}$ for 3 hours.

Tissue embedding and sectioning:The pancreatic tissues were then embedded into a mould filled with hot paraffin wax by using an embedding unit (Leica EG $1150 \mathrm{H}$ Embedding Centre) to form tissue blocks of testicular tissues. The blocks were then cut, trimmed and sectioned into 3-6 $\mu \mathrm{m}$-thick paraffin ribbon tissues by using a microtome (Leica RM 2235 Rotary Microtome).The wax ribbons were transferred into a water bath that was set at $41^{\circ} \mathrm{C}$ and were left for a duration in order to flatten the ribbons. Afterwards, the tissue sections were spread on microscope glass slides and were dried at $41^{\circ} \mathrm{C}$ on a hot plate. The slides were kept dry at room temperature overnight before being stained with haematoxylin and eosin (H\&E) staining. The H\&E stain was used as it is the most universal and traditional method for the examination of formalin-fixed, paraffinembedded tissue sections.

Tissue H \& E staining:slides containing the tissue samples were dipped in xylene 1 and xylene 2 for 2 minutes each. This was followed by hydration where the slides were immersed in alcohol in descending concentration (100\% absolute ethanol, $90 \%$ ethanol and $70 \%$ ethanol, 
respectively) for 2 minutes for each concentration of alcohol. The slides were then immersed in running water for 30 seconds before being placed into haematoxylin stain for 5 minutes. Haematoxylin acts as a basic dye and would cause basophilic structures which contain nucleic acids such as ribosomes and cell nucleus to appear purple$b_{l u e^{10}}$. Next, the slides were again washed in running tap water for 30 seconds and dipped into $1 \%$ acid alcohol for 3 seconds. Later, they were immersed in bluing solution, and in eosin solution for 5 minutes respectively, and then ran under running tap water for 30 seconds. Eosin acts as an acid dye that helps to stain cytoplasm, intracellular and extracellular proteins in red-pink. ${ }^{11}$

Table I Experimental regimen for STZ-induced hyperglycaemia rats' model $(n=6)$

\begin{tabular}{lllll}
\hline Group & Given name & Diet & $\begin{array}{l}\text { Induction of } \\
\text { hyperglycaemia }\end{array}$ & $\begin{array}{l}\text { Treatment dose/kg } \\
\text { Body weight }\end{array}$ \\
\hline A & Control Normal & Standard Chow Diet & None & Normal Saline \\
B & Insulin-treated & Standard chow diet & Yes & 2 IU Insulin \\
C & PCCA-treated & Standard chow diet & Yes & $30 \mathrm{mg}$ PCCA \\
D & PCBA-treated & Standard chow diet & Yes & $30 \mathrm{mg}$ PCBA \\
E & PCLA-treated & Standard chow diet & Yes & $30 \mathrm{mg}$ PCLA \\
F & Not Treated & Standard chow diet & Yes & None \\
\hline
\end{tabular}

Soon after, the slides were dried for a few minutes before being introduced into alcohol in ascending concentration, starting from $95 \%$ ethanol to $100 \%$ absolute ethanol. Lastly, the slides were dipped into xylene 4 and xylene 5 for 3 seconds and were then left to dry. Afterwards, DPX and cover slips were mounted onto the slides. The images of status and morphology of $\beta$-cell islets of Langerhans were observed under light microscope at X20 magnification, with $200 \mu \mathrm{m}$ scale bar while the diameter was determined using ImageJ software (Version 1.48).

\section{Statistical analysis}

The collected data was statistically analysed using Statistical Package for Social Sciences (SPSS) software (version 21.0 IBM) using one-way analysis of variance (ANOVA) and Repeated Measures ANOVA. The data was expressed as mean \pm standard deviation (SD). Furthermore, the difference in the mean was assessed using Tukey's and Bonferroni post-hoc test wherever appropriate and the difference in the means was regarded significant at $95 \%$ confidence interval $(\mathrm{p}<0.05)$.

\section{Results}

\section{Effects on the morphology of pancreas}

The pancreas of the control rats (Group-A) showed normal islets of Langerhans with abundant beta cells. The islets were surrounded by secretory acini containing cento acinar cells, excretory ducts and blood vessels (Figures 1 \&2). In the control hyperglycemic rats the islets appeared to be reduced in cellular density compared to the normal control and treatment groups. There were prominent cellular lesions within and around the periphery of the islets. The border between exocrine and endocrine pancreas appeared non-distinct (Figure 2). The pancreas of PCBA-treated (Figure 3), PCLA-treated (Figure 4) and PCCA-treated (Figure 5) rats showed islets and acinar cells comparable to the control group with some lesions. The islets showed a profusion of beta cells (Figures 3-6). Sections from the pancreas of insulin-treated (Figure B) rats also showed islets similar in architecture to the control group.

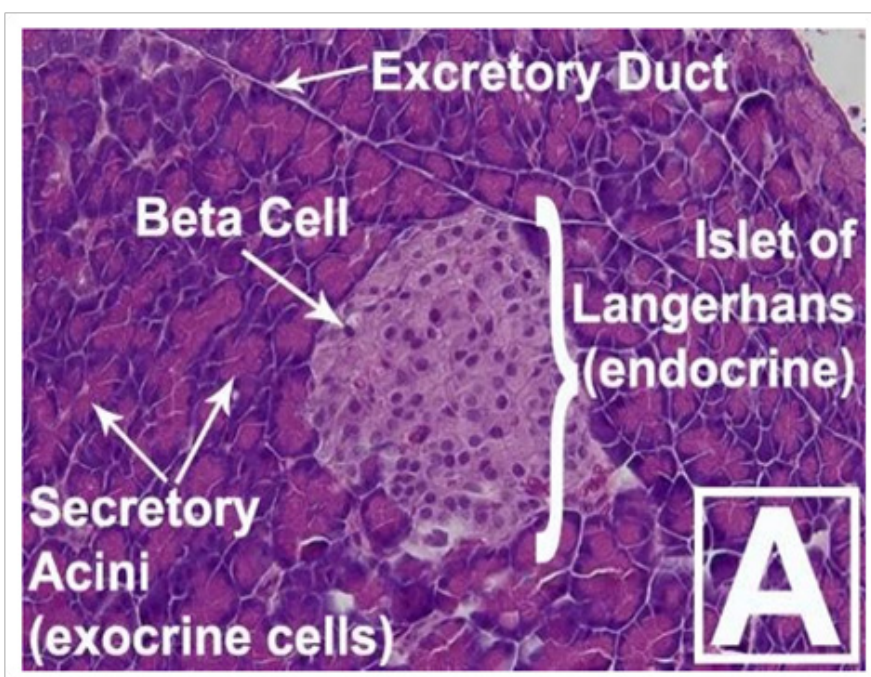

Figure I The morphology of the control group rat's pancreas (20X magnification)

\section{Discussion}

Since circulating levels of adiponectin are decreased in disease states of metabolic syndrome, an approach to replenish the levels by providing the protein, either in its recombinant form or protein extracted from other sources such as those used in the present study, can be implemented. The present study showed for the first time that a protein secreted by adipocytes have a positive effect in stimulating the secretion of adiponectin and insulin concentration in vivo when supplied exogenously. Protein from these sources could increase serum adiponectin and insulin levels in liver of treated group from STZ-induced hyperglycaemic rats. ${ }^{12}$ This directly confirms previous studies which have shown that adiponectin can promote insulin action and improve insulin resistance when supplied exogenously. ${ }^{13-15}$ Moreover, the present study elucidated the decrease 
in adiponectin concentration in hyperglycaemic rats without any treatment. This finding was consistent with experimental and clinical studies showing that plasma levels of adiponectin are decreased in obese and diabetes people. These results correlated well with the suggestion that the development of insulin resistance and diabetes are due to low plasma level of adiponectin. ${ }^{16}$

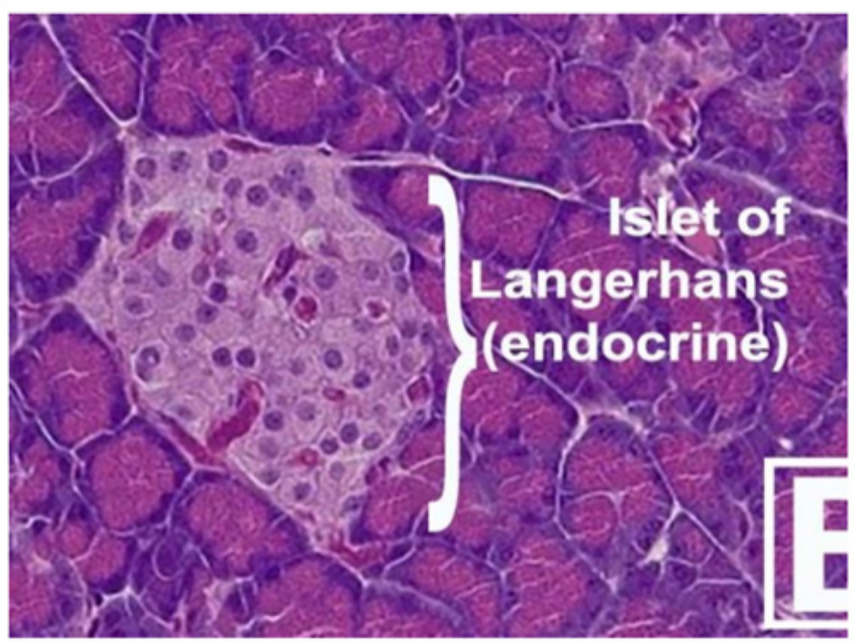

Figure 2 The morphology of the insulin-treated rat's pancreas (20X magnification).

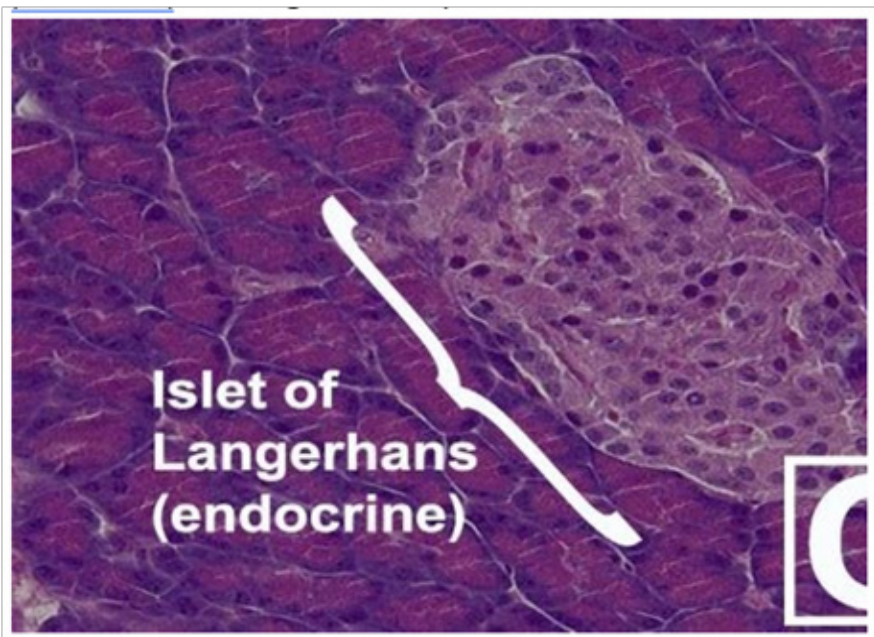

Figure 3 The morphology of the PCBA-treated rat's pancreas (20X magnification).

Other studies reported similar observations on adiponectin that acts as an anti-obesity, anti-diabetes and having an insulin-sensitizing property as well as regulate lipid and glucose homeostasis. Few studies on animal models of obesity and diabetes showed a reduced body weight, improved hyperglycaemia, improved hyperinsulinemia, as well as insulin resistance and lipid clearance after adiponectin treatment. ${ }^{13,14,17}$ In many (but not all) studies, administration of recombinant adiponectin resulted in improved hepatic insulin sensitivity, increased insulin secretion. ${ }^{17}$ (and have beneficial effects on body weight and hyperglycaemia, ${ }^{17-20}$ also suggested that plasma insulin concentration moderately increases in response to globular adiponectin fragment administration. Similarly, in the present study, the elevation of adiponectin and insulin concentration was observed after the treatment has been administrated, ${ }^{11}$ which indicated that PCBA-treated, PCCA-treated and PCLA-treated were potent insulin enhancers.

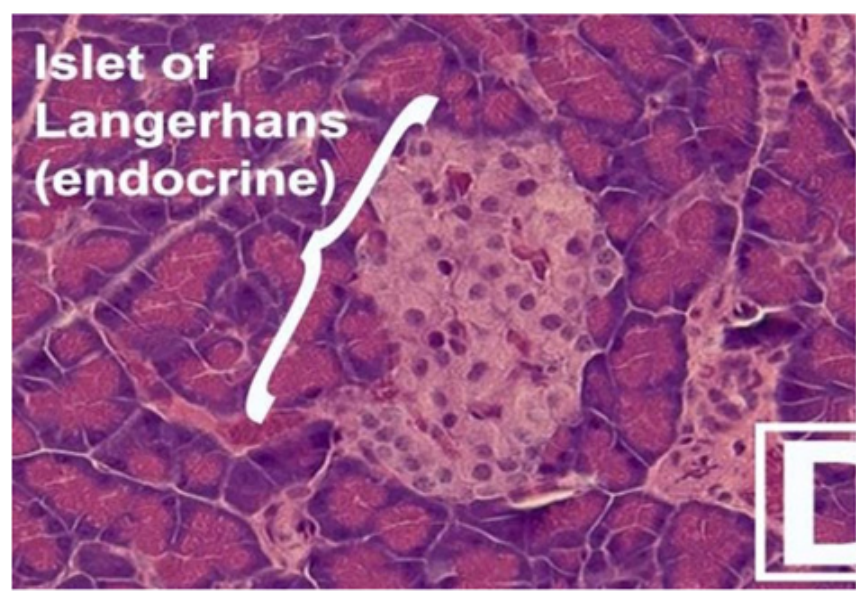

Figure 4 The morphology of the PCLA-treatedrat's pancreas (20X magnification).

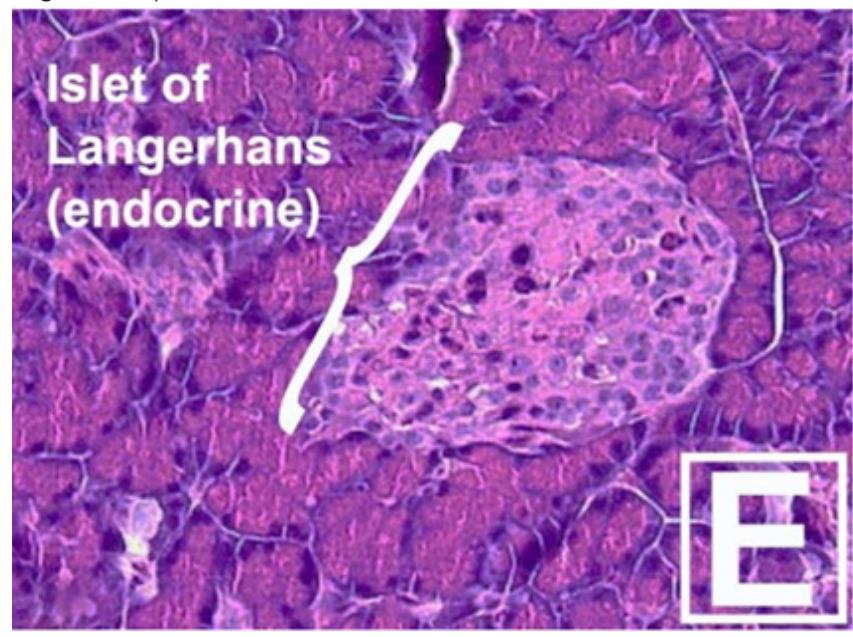

Figure 5 The morphology of the PCCA-treated rat's pancreas (20X magnification).

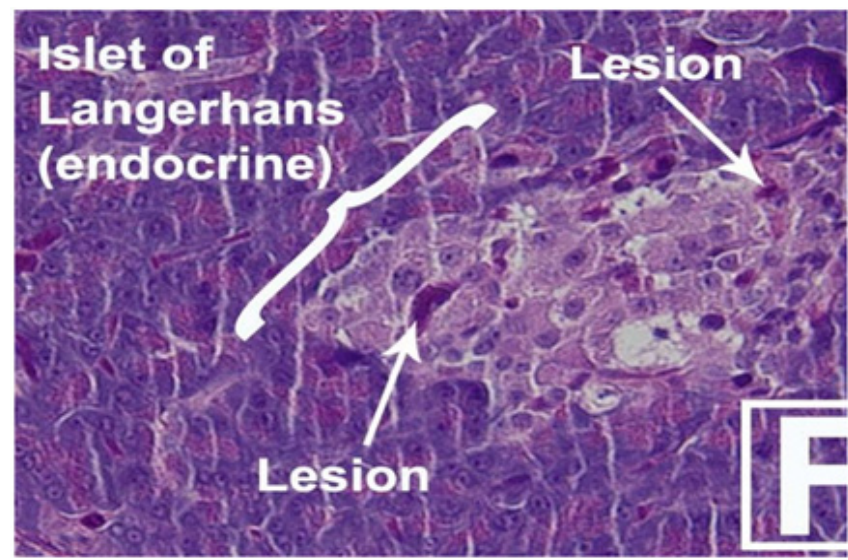

Figure 6 The morphology of the pancreas of the hyperglycemic rats without treatment (20X magnification).

Commercial production of a bioactive full-length form of adiponectin that has a reasonable half-life would be a tough and 
expensive proposition. Therefore, an alternative approach using a truncated version of the protein was used in the present study. Although there is currently no direct clinical evidences demonstrating that adiponectin is effective in treating disorders associated with the metabolic syndrome, various therapeutic benefits of recombinant adiponectin have been extensively studied in in vivo models. ${ }^{21}$ The present study used the low-cost method of protein to be utilized for the metabolic syndrome and associated factors. The previous studies used specific purified and characterised adiponectin, whereas the present study was more to the recently secreted adipokines. These protein sources were mixtures of various types of adipokines such as leptin, RBP4, visfatin, resistin, TNF $\alpha$, IL-6, adiponectin and others. In addition, the protein also comprised of few amino acids such as methionine, lysine, threonine, tryptophan, isoleucine, leucine, histidine, valine, phenylalanine and arginine..$^{22-24}$ This would be of clinical significance with lower cost that these protein extracts can possibly obtained and consumed for the treatment of the diseases in the future.

Furthermore, it is now recognized that both major types of DM affect $\beta$-cells mass and insulin secretion. ${ }^{25}$ Due to this fact, it accelerated the interest in targeting the pancreatic $\beta$-cells. It has been proposed that these cells have the potential in improving hyperglycaemic state and could potentially reduce the progression of diabetic complication. Most studies used a single large dose of STZ injection for experimental purposes in order to determine the therapeutic strategies for replenishing $\beta$-cells. ${ }^{26,27} \mathrm{STZ}$ is transported into the cell by a glucose transport protein, known as GLUT 2, which is similar to glucose but is not recognized by the other glucose transporters. Thus, since these cells have a higher level of GLUT 2, they cause toxicity to beta cell of pancreas..$^{28,29} \mathrm{~A}$ study from Kawada ${ }^{30}$ showed that STZ damages the pancreas by generating reactive oxygen and increase oxidative stress as beta cells are poor in free radical scavenging capacity. Due to this situation, STZ selectively damages the pancreatic $\beta$-cells by making the cells less active and this results in a diabetic state. ${ }^{31}$ The present study targeted the $\beta$-cells being damaged by the induction of STZ for possible regeneration with the supplementation of the sources of protein. It is well known that the $\beta$-cells regeneration is associated with metabolic diseases. ${ }^{32}$ Therefore, any modulation in the dietary or pharmacological sources that can help and regenerate the $\beta$-cells would essentially regress the secondary effects.

In the present study, examination of $\mathrm{H} \& \mathrm{E}$ stained sections from the control group showed the pancreas to have a normal histological structure. The islets of Langerhans appeared rounded, or oval areas inside the pancreatic lobules showed islets with nearly regular outlines and almost normal cell morphology. In non-treated group, STZ caused severe degenerative changes in the pancreatic islets, mainly at the centre of the islets. An apparent reduction in the size and number of islets was also noted. Islet lesions and destruction of beta cells were evident in the non-treated diabetic group. In the present study, comparable results were recorded as those to the findings from previous studies where STZ injured the beta cells of the pancreas. ${ }^{33}$

In this study, the supplementation of protein from these sources resulted in improvement of regeneration of $\beta$-cells and reversal of islets lesions. This was clinically significant and the positive improvement of the up regulation of insulin secretion and reduction in hyperglycaemia is recorded in the treated group. This might be due to the presence of adiponectin in the protein, which is known as an insulin sensitizing protein that is capable to increase $\beta$-cells proliferation and stimulation of insulin secretion. Similar results have been reported by other studies, which suggested a putative protective effect of characterized adiponectin that could counteract the apoptosis on pancreatic $\beta$-cell. Those findings suggest that adiponectin might have direct effect on insulin secretion. ${ }^{34,35}$ The ability of adiponectin to protect against apoptosis to increase cellular viability, glucosestimulated insulin sensitivity (GSIS) as well as its ability to potentiate the insulin response in beta cells independent of activating AMPK which is a negative regulator of beta cell function. ${ }^{36}$ The role of adipokines and the possible role in the regeneration of pancreatic $\beta$-cells crucial due to their inflammatory and metabolic importance in the diabetes. This suggests that the supplementation of $(\mathrm{C})$ protein containing beef adiponectin (PCBA), (D) protein containing lamb adiponectin (PCLA), (E) protein containing chicken adiponectin (PCCA) (Figure 5.3) protects the pancreas against STZ-induced damages.

\section{Conclusion}

The present study showed significant increase in the concentration of adiponectin and insulin after the treatment, which suggested that PCBA, PCCA and PCLA-treated may be potentially insulin enhancers. This study also demonstrated that these protein sources may have protecting effect on the pancreas against STZ-induced damages to $\beta$-cells of the rats as well as inducing islets regeneration. Considering the therapeutic potentials of the proteins extracted from the specified sources on liver tissues and pancreatic $\beta$-cells, these sources should be further investigated for the efficacy of the metabolic diseases. The results from the present study provided convincing evidences for the potential success of such an approach and warrants further optimization for these proteins to be studied at a molecular level.

\section{Acknowledgments}

The authors thankfully acknowledge the Ministry of Education Malaysia for the financial assistance and Research Management Centre, and Kulliyyah of Allied Health Sciences, International Islamic University Malaysia for facilitating the project.

\section{Conflicts of interest}

The funding of this project was from the MyRA Incentive Research Grant Scheme (Grant Number MIRGS 13-01-002-0001).

\section{Funding}

The funding source of this project was funded by Myra Incentive Research Grant Scheme (Grant Number MIRGS 13-01-002-0001).

\section{References}

1. Gutierrez GD, Gromada J, Sussel L. Heterogeneity of the Pancreatic Beta. Frontiers Genetics. 2017;8(22):1-9.

2. Matsuzawa Y, Funahashi T, Kihara S, et al. Adiponectin and Metabolic Syndrome. Arterioscler Thromb Vasc Biol. 2004;24:29-33.

3. Hong Ma, Fan Cui, Jing-Jing, et al. Therapeutic effects of globular adiponectin in diabetic rats with nonalcoholic fatty liver disease. World Journal of Gastroenterology. 2014;20(40):14950-14957.

4. Hiroyuki Kase, Yoshiyuki Hattori, Teruo Jojima, et al. Globular Adiponectin Induces Adhesion Molecule Expression Through the Sphingosine Kinase Pathway in Vascular Endothelial Cells. Life Sciences. 2007;81(11):939-943. 
5. Bligh EG, Dyer WJ. A Rapid Method of Total Lipid Extraction and Purification. Canadian Journal of Biochemistry and Physiology. 1959;37(8):911-917.

6. Vaisar T. Proteomic analysis of lipid-protein complexes. Journal of Lipid Research. 2009;50:781-786.

7. Sajic T, Hopfgartner G, Szanto I, et al. Comparison of Three DetergentFree Protein Extraction Protocols for White Adipose Tissue. Analytical Biochemistry. 2011;415(2):215-217.

8. AH Berg, TP Combs, X Du, M Brownlee, et al. The adipocytesecreted protein Acrp30 enhances hepatic insulin action. Nat Med. $2001 ;(8): 947-953$

9. Miki Okada-Iwabu, Toshimasa Yamauchi, Masato Iwabu, et al. Smallmolecule AdipoR agonist for type 2 diabetes and short life in obesity. Diabetes and Metabolism J. 2013;503:493-499.

10. Søren Tullin, Anette Sams, Jakob Brandt, et al. Recombinan Adiponectin Does Not Lower Plasma Glucose in Animal Models of Type 2 Diabetes. Plos One. 2012;(10):13-19.

11. Ruegg M, Meinen S. Histopathology in Hematoxylin \& Eosin stained muscle sections. TREAT-NMD Neuromuscular Network. 2014;1-9.

12. Combs TP, Berg AH, Obici S, et al. Endogenous Glucose Production is Inhibited by the Adipose-Derived Protein Acrp30. Journal of Clinical Investigation. 2001;108(12):1875-1881.

13. Yamauchi T, Kamon J, Waki H, et al. The fat-derived hormone adiponectin reverses insulin resistance associated with both lipoatrophy and obesity. Nature Medicine. 2001;7(8):941-946.

14. Lina Zhao, Zhuo Fu, Jing Wu, et al. Globular Adiponectin Ameliorates Metabolic Insulin Resistance via AMPK-Mediated Restoration of Microvascular Insulin Responses. Journal Physiology. 2015;17:4067_ 4079

15. Trujillo ME, Scherer PE. Adiponectin - Journey from an Adipocyte Secretory Protein to Biomarker of the Metabolic Syndrome. Journal of Internal Medicine. 2005;257(2):167-175.

16. J Fruebis, T S Tsao, S Javorschi, et al. Proteolytic cleavage product of $30-\mathrm{kDa}$ adipocyte complement-related protein increases fatty acid oxidation in muscle and causes weight loss in mice. PNAS 2001;98(4):2005-2010.

17. M Okamoto, M Ohara-Imaizumi, N Kubota, et al. Adiponectin Induces Insulin Secretion in Vitro and in Vivo at a Low Glucose Concentration. Diabetologia. 2008;51:827-835

18. Kusminski CM, Bickel PE, Scherer PE. Targeting adipose tissue in the treatment of obesity-associated diabetes. Nature Reviews Drug Discovery. 2016;15(9):639-660.

19. Turer AT, Scherer PE. Adiponectin: Mechanistic Insights and Clinical Implications. Diabetologia. 2012;55(9):2319-2326.

20. Gu W, Li Y. The Therapeutic Potential of the Adiponectin Pathway. Biodrugs. 2012;26(1):1-8

21. Hascik P, Trembecka L, Bobko M, et al. Amino Acid Profile of Broile Chickens Meat Fed Diets Supplemented with Bee Pollen and Propolis. Journal of Apicultural Research. 2016;55(4):324-334.
22. Honggyun Kim, Hyun Wook Do, Heajung Chung. A Comparison of the Essential Amino Acid Content and the Retention Rate by Chicken Part according to Different Cooking Methods. Korean J Food Sci. 2017;37(5):626-634

23. Soriano J. Chemical Composition and Nutritional Content of Raw Meat. In Handbook of Poultry Science and Technology. 2010;1:467489.

24. Meier JJ, Riccardo CB. Role of Reduced B-Cell Mass Versus Impaired B-Cell Function in the Pathogenesis of Type 2 Diabetes. Diabetes Care. 2013;36:S113-S119.

25. Nurdiana S, Goh YM, Ahmad H, et al. Changes in pancreatic histology , insulin secretion and oxidative status in diabetic rats following treatment with Ficus deltoidea and vitexin. BMC Complementary and Alternative Medicine. 2017;17(290):1-17.

26. Josie XZhou, Sangeeta Dhawan, Hualin Fu, et al. Combined Modulation of Polycomb and Trithorax Genes Rejuvenates $\beta$ cell Replication. The Journal of Clinical Investigation. 2013;123(11):4849-4858.

27. Schnedl WJ, Ferber S, Johnson JH. et al. STZ Transport and Cytotoxicity Specific Enhancement in GLUT2-Expressing Cells. Diabetes. 1994;43:1326-1333.

28. Zhiyong W, Gleichmann H. GLUT2 in Pancreatic Islets: Crucia Target Molecule in Diabetes Induced With Multiple Low Doses of Streptozotocin in Mice. Diabetes. 1998;47(1):50-56.

29. Kawada J. New Hypotheses for the Mechanisms of Streptozotocin and Alloxan Inducing Diabetes Mellitus. Yakugaku Zasshi. 1992;112(11):773-791.

30. Junod A, Lambert AE, Orci L, et al. Experimental Biology and Medicine. Experimental Biology and Medicine Can. 1967;126:201205

31. Heindel JJ, Blumberg B, Cave M, et al. Metabolism Disrupting Chemicals and Metabolic Disorders. Reproductive Toxicology. 2017;68:3-33

32. Ukwenya VO, JO Ashaolu, Adeyemiv DO, et al. Antihyperglycemic Activities of Methanolic Leaf Extract of anacardium occidentale (Linn.) on the Pancreas of Streptozotocin-Induced Diabetic Rats. Journal of Cell and Animal Biology. 2012;6(11):169-174.

33. Kharroubi I, Rasschaert J, Eizirik DL, et al. Expression of adiponectin receptors in pancreatic. Biochemical and Biophysical Research Communications. 2003;312:1118-1122.

34. Rakatzi I, Mueller H, Ritzeler O, et al. Adiponectin Counteracts Cytokine- and Fatty Acid-Induced Apoptosis in the Pancreatic BetaCell Line INS-1. Diabetologia. 2004;47:249-258.

35. Wijesekara N, Krishnamurthy M, Bhattacharjee A, et al. Adiponectininduced ERK and Akt Phosphorylation Protects against Pancreatic Beta Cell Apoptosis and Increases Insulin Gene Expression and Secretion. The Journal of Biological Chemistry. 2010;285(44):33623-33631.

36. Lee MW, Lee M, Oh KJ. Adipose Tissue-Derived Signatures for Obesity and Type 2 Diabetes: Adipokines, Batokines and MicroRNAs. J Clin Med. 2019;14;8(6):854. 